\title{
Understanding the Influence of Interface Morphology on the Performance of Perovskite Solar Cells
}

\author{
Manuel Salado ${ }^{1,+}$ (iD , Laura Calió ${ }^{2,+}$, Lidia Contreras-Bernal ${ }^{3}$, Jesus Idígoras ${ }^{3}$, \\ Juan Antonio Anta 3 (iD, Shahzada Ahmad ${ }^{1,2,4}$ and Samrana Kazim 1,2,* \\ 1 BCMaterials, Basque Center for Materials, Applications and Nanostructures, Bld. Martina Casiano, \\ UPV/EHU Science Park, Barrio Sarriena, s/n, 48940 Leioa, Spain; manuel.salado@bcmaterials.net (M.S.); \\ shahzada.ahmad@bcmaterials.net (S.A.) \\ 2 Abengoa Research, Abengoa, c/Energía Solar no. 1, Campus Palmas Altas, 41014 Sevilla, Spain; \\ calio.laura@gmail.com \\ 3 Area de Química Física, Universidad Pablo de Olavide, E-41013 Sevilla, Spain; lconber@upo.es (L.C.-B.); \\ jaidileo@upo.es (J.I.); jaantmon@upo.es (J.A.A.) \\ 4 IKERBASQUE, Basque Foundation for Science, 48013 Bilbao, Spain \\ * Correspondence: samrana.kazim@bcmaterials.net \\ + These authors contributed equally to this work.
}

Received: 23 May 2018; Accepted: 17 June 2018; Published: 25 June 2018

\begin{abstract}
In recent years, organo-halide perovskite solar cells have garnered a surge of interest due to their high performance and low-cost fabrication processing. Owing to the multilayer architecture of perovskite solar cells, interface not only has a pivotal role to play in performance, but also influences long-term stability. Here we have employed diverse morphologies of electron selective layer (ESL) to elucidate charge extraction behavior in perovskite solar cells. The $\mathrm{TiO}_{2}$ mesoporous structure (three-dimensional) having varied thickness, and nanocolumns (1-dimensional) with tunable length were employed. We found that a $\mathrm{TiO}_{2}$ electron selective layer with thickness of about c.a. $100 \mathrm{~nm}$, irrespective of its microstructure, was optimal for efficient charge extraction. Furthermore, by employing impedance spectroscopy at different excitation wavelengths, we studied the nature of recombination and its dependence on the charge generation profile, and results showed that, irrespective of the wavelength region, the fresh devices do not possess any preferential recombination site, and recombination process is governed by the bulk of the perovskite layer. Moreover, depending on the type of ESL, a different recombination mechanism was observed that influences the final behavior of the devices.
\end{abstract}

Keywords: electron transport material; titanium oxide; charge dynamics; metal-halides perovskites

\section{Introduction}

During recent years, organic-inorganic halide perovskite solar cells (PSCs) have made colossal progress, competing head-to-head at lab scale with mature Silicon-based or other thin-film-based photovoltaic technologies [1]. The rapid increase in terms of power conversion efficiency (PCE) in just a few years [2-4] has been possible due to the exploration of rational charge selective contacts, interface optimization and the compositional engineering of perovskites $[5,6]$. The attractiveness of exploiting organic-inorganic halide perovskite is mainly due to its broad and high absorption co-efficient, along with its ambipolar character to transport electrons and holes [7]. Although the current record PCE values in PSCs have reached 22.7\% [8], a thorough understanding of the processes involved in charge transport and recombination between layers and inside the perovskite layer is paramount.

Generally, in the case of photovoltaics, the incident photons create free carriers when they are absorbed by the semiconducting material. In the case of PSCs, these free carriers (electrons and holes) 
travel through the perovskite to the interface of respective charge selective contacts. Depending on the deposition techniques [9-12] and the composition of the perovskite $[6,13,14]$ used, energetic disorder may exist mainly in the grain boundaries, which act as recombination points. In order to minimize these recombination sites, extensive effort has been made to improve the quality of the perovskite layers through compositional engineering [6], interface passivation [15,16], or processing methods such as gas-phase $[17,18]$ or vacuum assisted deposition $[19,20]$. However, interfaces are vulnerable to losses due to energy-level mismatch, un-intimate contact or interfacial defects which lead to high charge accumulation, which causes a drop in the performance of the solar cell, especially in open-circuit conditions [21,22]. Thus, it is vital to understand and control charge extraction across the interfaces in order to minimize energy loss and improve device performance.

Among the diverse device structures [23] investigated to date-planar [24], mesoporous [25] and inverted [26] - mesoporous-structure-based devices employing $\mathrm{TiO}_{2}$ [27] and Spiro-OMeTAD [28] as the selective contacts for electrons and holes extraction respectively, yielded the best PCE and stability. Considerable research efforts have been focused on the hole selective layer (HSL), not only due to the high production cost of Spiro-OMeTAD, but also due to UV-instability and other disadvantages such as the need for dopants, which subsequently affects the performance of PSCs.

$\mathrm{TiO}_{2}$ is the most ubiquitous electron selective contact in mesoporous-structure-based devices. In order to improve charge extraction and reduce nanoparticle clustering, different strategies have been implemented in the past few years. For instance, Grätzel and Ahmad et al. employed $\mathrm{Y}^{-\mathrm{TiO}_{2}}$ film with the aim of improving the conductivity of $\mathrm{TiO}_{2}$ [29]. The results showed an increment in PCE, mostly due to better charge extraction after modifying the $\mathrm{TiO}_{2}$ layer. Following a similar strategy, Cojocaru et al. [30] carried out a post-treatment to the blocking $\mathrm{TiO}_{2}$ layer with $\mathrm{TiCl}_{4}$ and demonstrated an efficiency enhancement of $3 \%$ when comparing reverse- versus forward-measurement directions. In a similar fashion, Grätzel et al. [31] and Friend et al. [32] demonstrated beneficial effects when mesoporous $\mathrm{TiO}_{2}$ is post-treated with $\mathrm{Li}^{2+}$. It was argued that lithium salt can passivate the interface and can reduce the trap density. These effects led to the fabrication of devices with not only reduced hysteresis and favored electron extraction, but also improved stability.

In the recent past, electrochemical analysis such as impedance spectroscopy (IS), Intensity-modulated photocurrent spectroscopy (IMPS) and intensity-modulated photovoltage spectroscopy (IMVS) are being employed to elucidate charge recombination, accumulation and transport [33,34]. Different approaches have been proposed, from the typical perovskite device architecture where the electron selective layer (ESL) is either high temperature processed mesoporous $\mathrm{TiO}_{2}$, or low temperature processed $\mathrm{TiO}_{2}$ in a simple planar structures that are ideal for flexible configurations. Previously, we reported [35] how the use of $\mathrm{TiO}_{2}$ nanocolumns affects the charge dynamics on devices, along with improvement to stability.

Herein, we report the role of $\mathrm{TiO}_{2}$ microstructure (3-dimensional and 1-dimensional) and thickness on charge dynamic studies in polycrystalline layers of methyl ammonium lead triiodide $\left(\mathrm{MAPbI}_{3}\right)$. The optimization of the ESL thickness was studied by IS, to optimize charge separation and elucidate its role on charge dynamics, suggesting that, irrespective of its microstructure, an electron extraction layer with a thickness of ca. $100 \mathrm{~nm}$ produces better device performance in our experimental conditions.

\section{Materials and Methods}

\subsection{Materials}

All chemicals were commercial products and procured from either Sigma-Aldrich (St. Louis, $\mathrm{MO}, \mathrm{USA}$ ) or Acros organics (Geel, Belgium) and were employed as such. 2,2',7,7'-tetrakis( $N, N$-di-pmethoxyphenyamine)-9,9-spirobifluorene (Spiro-OMeTAD) was acquired from Merck KGaA (Darmstadt, Germany). Methylamine iodide, $\mathrm{CH}_{3} \mathrm{NH}_{3} \mathrm{I}$ (MAI) was bought from Greatcells Solar (Queanbeyan, New South Wales, Australia) and $\mathrm{PbI}_{2}$ were bought from TCI (Tokyo, Japan). Chlorobenzene and anhydrous DMSO were obtained from Sigma-Aldrich (St. Louis, MO, USA). Acetone, acetonitrile solvents were bought from Acros organics. 


\subsection{Electron Selective Layer (ESL) Deposition}

Vertically aligned nanocolumns with a thickness of 100 or $200 \mathrm{~nm}$ were prepared at room temperature by physical vapor deposition at oblique incidence (GLAD-PVD) in an electron beam evaporator (Advanced Products and Technologies $\mathrm{GmbH}$, Nurtingen, Germany), as described in previous publications [35,36]. The deposition time was controlled to achieve two different nanostructured thicknesses, i.e., 100 or $200 \mathrm{~nm}$. In case of $\mathrm{TiO}_{2}$ mesoporous layer (30NRD, Greatcells Solar, Queanbeyan, Australia), to obtain different thicknesses, mesoporous stock solutions with different dilution (1:7 and 1:3.5 w/w) were prepared and spun-coated at $4000 \mathrm{rpm}$ for $20 \mathrm{~s}$. For the fabrication of planar devices, no such layer was used. All the ESL-based substrates were then annealed up to $450{ }^{\circ} \mathrm{C}$ in a progressive manner for $2 \mathrm{~h}$.

\subsection{Device Preparation}

To fabricate the PSCs, laser-etched FTO-coated glass (TEC15, Pilkington, Tokyo, Japan) was used. Prior to use, the electrodes were cleaned using Hellmanex solution and washed with deionized water. Subsequently, they were ultrasonicated for $25 \mathrm{~min}$ at $60^{\circ} \mathrm{C}$ in acetone, 2-propanol, and finally dried using nitrogen blow. The compact layer (hole-blocking layer) was made up of $\mathrm{TiO}_{2}$, deposited by spray pyrolysis at $450{ }^{\circ} \mathrm{C}$ by diluting $1 \mathrm{~mL}$ of titanium diisopropoxide bis(acetyl acetonate) precursor solution (75\% in 2-propanol, Sigma-Aldrich) in $19 \mathrm{~mL}$ of pure ethanol and dry air as carrier gas. These substrates were then kept for a further $30 \mathrm{~min}$ at $450{ }^{\circ} \mathrm{C}$. Once the $\mathrm{TiO}_{2}$ deposited electrodes attained room temperature, they were immersed in a $0.02 \mathrm{M} \mathrm{TiCl}_{4}$ solution in deionized water at $70{ }^{\circ} \mathrm{C}$ for $30 \mathrm{~min}$ to form a homogeneous layer. After this treatment, the electrodes were washed by using deionized water and annealed at $500{ }^{\circ} \mathrm{C}$ for $30 \mathrm{~min}$, and then allowed to cool down to room temperature.

For deposition of the perovskite layer, $1.2 \mathrm{M}$ of $\mathrm{PbI}_{2}$ and MAI precursor solutions (1:1 ratio), in DMSO were prepared inside an argon-filled glovebox $\left(\mathrm{H}_{2} \mathrm{O}\right.$ level: $<1 \mathrm{ppm}$ and $\mathrm{O}_{2}$ level: $\left.<10 \mathrm{ppm}\right)$ and left for stirring overnight at $80^{\circ} \mathrm{C}$. The perovskite layer was deposited using the so called one-step method followed by solvent engineering; for this the precursor solution was spun-coated on top of the mesoporous layer at $1000 \mathrm{rpm}$ for $10 \mathrm{~s}$ and then $6000 \mathrm{rpm}$ for $20 \mathrm{~s}$. Chlorobenzene was dripped during the second stage of spinning process. Following this the electrodes were transferred to a hotplate and annealed at $100{ }^{\circ} \mathrm{C}$ for $1 \mathrm{~h}$ to allow the formation of perovskites. The hole transport layer was then deposited on top of the perovskites; for this $35 \mu \mathrm{L}$ of a Spiro-OMeTAD solution was then spun-coated at $4000 \mathrm{rpm}$ for $20 \mathrm{~s}$. Spiro-OMeTAD material $(70 \mathrm{mM})$ was dissolved in $1 \mathrm{~mL}$ of chlorobenzene and standard additives such as $17.5 \mu \mathrm{L}$ of a lithium bis(trifluoromethylsulphonyl)imide (LiTFSI) stock solution (520 mg of LiTFSI in $1 \mathrm{~mL}$ of acetonitrile), $21.9 \mu \mathrm{L}$ of a FK209 (Tris(2-(1H-pyrazol-1-yl)-4-tert-butylpyridine) cobalt(III)Tris(bis(trifluoromethylsulfonyl)imide))) stock solution (400 $\mathrm{mg}$ in $1 \mathrm{~mL}$ of acetonitrile), and $28.8 \mu \mathrm{L}$ of 4 -tert-butylpyridine ( $t$-BP). The device was finished by depositing $80 \mathrm{~nm}$ of gold as a cathode layer, using thermal evaporation under a vacuum level between $10^{-6}$ to $10^{-5}$ torr.

For IS measurements, light sources were provided using red $(\lambda=635 \mathrm{~nm})$ and blue $(\lambda=465 \mathrm{~nm})$ light emitting diodes (LEDs) in a broad range of DC light intensities. By doing so, the devices could be probed on two different optical penetrations [37]. To record the impedance spectra, a response analyzer module ((PGSTAT302N/FRA2, Metrohm Autolab, Utrecht, Netherlands) was employed, and $20 \mathrm{mV}$ perturbation in the $10^{7}-10^{-2} \mathrm{~Hz}$ range was applied for the measurements. The voltage drop (arising due to series resistance) was avoided by performing the measurements at the open-circuit potential, and the Fermi level (linked to the open-circuit voltage) was fixed by the DC (bias) illumination intensity. The different response under blue and red light was compensated by monitoring all parameters and was plotted as a function of the open-circuit potential generated by individually bias light. 


\section{Results and Discussion}

Figure 1a represents a schematic of the fabricated solar cell, in which the different layers (FTO/bl$\mathrm{TiO}_{2} /$ mesoporous or nanocolumns $\mathrm{TiO}_{2} / \mathrm{CH}_{3} \mathrm{NH}_{3} \mathrm{PbI}_{3} /$ Spiro-OMeTAD/Au) can be visualized. In order to observe morphological difference of the interface between the absorber layer and the electron extraction layer, scanning electron microscopy (SEM, Hitachi, Tokyo, Japan) experiments were performed. Figure 1b,c represents the cross-sectional SEM images of the fabricated devices having different thicknesses of mesoporous structure. The thickness of the mesoporous structure was tuned by varying the dilution rate of the $\mathrm{TiO}_{2}$ paste; for example, the more diluted $\mathrm{TiO}_{2}$ paste led to a thin layer (Figure 1 and Table S1). In case of $\mathrm{TiO}_{2}$ nanocolumns, the length of columns was varied by increasing the deposition time. Considering the values in Table S1, the total thickness of photoactive layer (mesoporous \& perovskite capping layer) was c.a. $300 \mathrm{~nm}$. It can be seen from the figures that the thickness of the perovskite capping layer was also altered when the dilution rate was modified, having a strong influence in the series resistance of the device (Figure S1). The aim of using different microstructures (3D and 1D) was to optimize the effective thickness for ideal perovskite infiltration and electron extraction. According to the current density-voltage $(J-V)$ curves (Figure 2), the best configuration was found to be 1:7, which allowed a thickness of around $100 \mathrm{~nm}$ (Table S1).

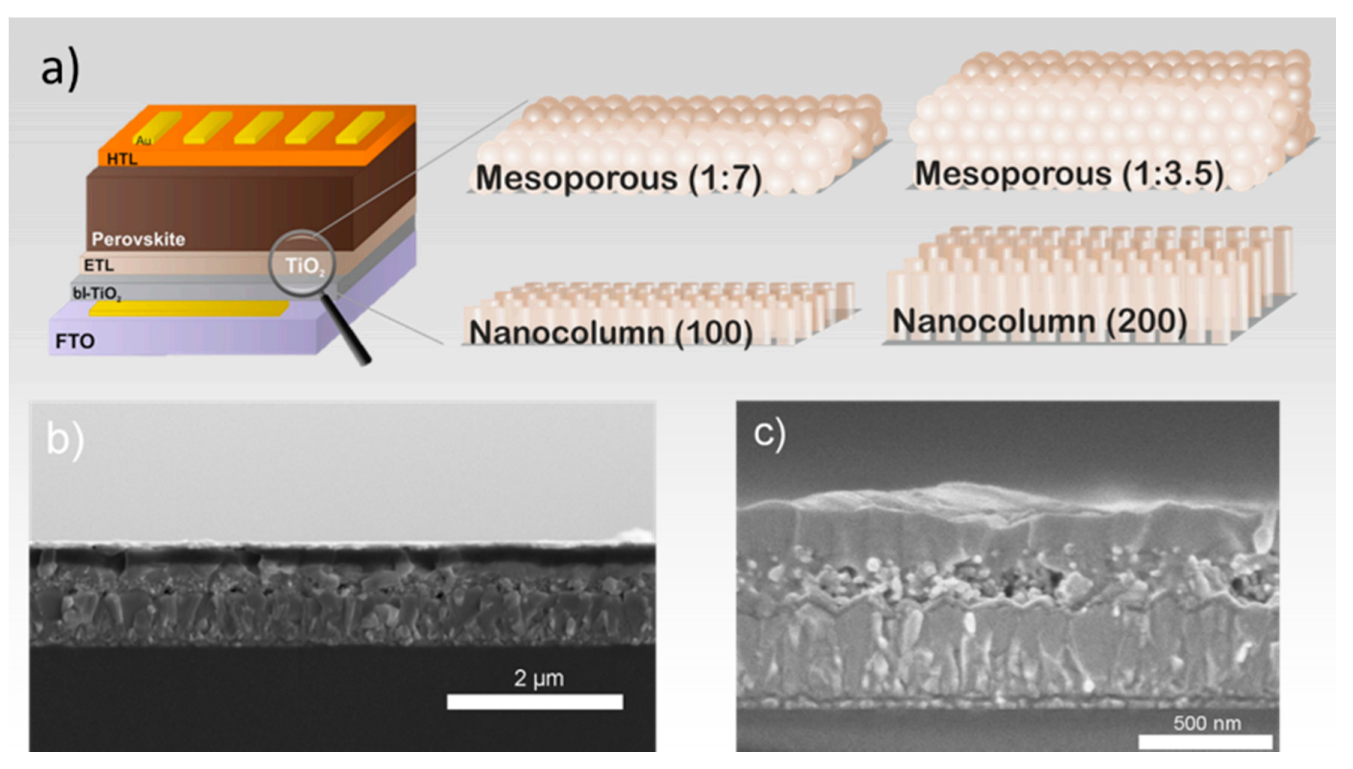

Figure 1. (a) Cross-sectional device scheme and electron selective layer (ESL) used, (b) scanning electron microscopy (SEM) image of PSC with 1:7 $\mathrm{TiO}_{2}$ mesoporous structure and (c) SEM image of PSC with 1:3.5 $\mathrm{TiO}_{2}$ mesoporous structure.

$\mathrm{TiO}_{2}$ nanostructure and its thickness can influence the properties of the layer deposited atop of it. Earlier, we have presented the cross-sectional image of 1-D $\mathrm{TiO}_{2}$ nanocolumns (100 and $200 \mathrm{~nm}$ ) [35]. To study the role of $\mathrm{TiO}_{2}$ microstructure effects on the band gap of the perovskite, we calculated the optical band gap of devices having different ESL configurations using the Tauc plot method. The absorption coefficient $(\alpha)$ was calculated from measured absorbance spectra (Figure S2a) and a Tauc plot $(\alpha h v)^{2}$ vs. $h v$ was used to calculate the optical direct band gap as shown in Figure S2b. The linear extrapolation of this curve to intercept the horizontal hv axis gives the value of band gap $(\sim 1.59 \mathrm{eV})$.

Figure 2 illustrates the $J-V$ curves of fabricated PSCs using different ESL under standard conditions (100 $\mathrm{mW} \cdot \mathrm{cm}^{-2}-\mathrm{AM} 1.5$ illumination) at room temperature. Table 1 summarizes the different photovoltaic parameters of the best-performing devices for each configuration, while their statistical data are listed in Table S2. As expected, the thickness of the ESL was found to influence the photovoltaic performance. 
A lower value of $V_{\text {oc }}$ was noted $\left(V_{\text {oc }}=930 \mathrm{mV}\right)$ with a thicker $\mathrm{TiO}_{2}$ layer (nanocolumns- $200 \mathrm{~nm}$ and nanoparticles-1:3.5), in comparison to the thinner $\mathrm{TiO}_{2}$ ESLs (nanocolumns-100 nm and nanoparticles-1:7), or planar devices $(0 \mathrm{~nm})$. Although no significant changes were observed in terms of the $J_{\mathrm{sc}}$, and regardless of the nanostructure and thickness of the ESLs, all devices gave $J_{\mathrm{sc}}$ in the range of $18-19 \mathrm{~mA} \cdot \mathrm{cm}^{-2}$. These results are in line with the absorbance spectra obtained for the different configuration (Figure S2). Devices fabricated with mesoporous layer (1:7, Ø30 nm) and $100 \mathrm{~nm}$ nanocolumns yielded best PCE, as well as lower series resistance (Figure S1).

In PSCs, the series resistance $\left(R_{\mathrm{S}}\right)$ is known as a crucial factor which can affects the device fill factor, and the $R_{\mathrm{S}}$ depends not only on bulk resistance of the photoactive layer, but also on metallic contacts and contact resistance at each interface. The $R_{\mathrm{S}}$ of the devices (obtained from the software by fitting the $J-V$ curve) based on $100 \mathrm{~nm} \mathrm{TiO}_{2}$ nanocolumns and thin mesoporous layers (1:7 dilutions, thickness around $125 \mathrm{~nm}$ ) show a lower $R_{\mathrm{s}}$ value than the $200 \mathrm{~nm}$ nanocolumns and thick mesoporous layer (1:3.5). The reduced value of $R_{\mathrm{s}}$ agrees with the enhanced FF for thin $\mathrm{TiO}_{2}$ ESLs (mp-1:7 and $100 \mathrm{~nm} \mathrm{NC)}$, irrespective of their morphology.

Dissimilarities in device behavior can be also analyzed from the dark-current measurements (represented by the hollow symbols in Figure 2). It is known that the $V_{\text {oc }}$ is strongly related to the onset voltage point of the device measured in the dark under a forward bias, and delay in the onset voltage point of the device will result in high $V_{\text {oc }}$. Devices prepared with mesoporous $\mathrm{TiO}_{2}$ layer (1:7, Ø30 nm), $100 \mathrm{~nm} \mathrm{TiO} 2$ nanocolumns and planar devices exhibit comparatively lower dark current and late switch-on of the devices under forward bias than the thicker mesoporous (1:3.5, $\varnothing 30 \mathrm{~nm}$ ), and $200 \mathrm{~nm}$ nanocolumns. The delay in the onset of the dark current for the abovementioned devices is well supported, with comparatively high values of $V_{\text {oc }}$ (Table 1), indicating reduced charge recombination rates in thinner ESLs, which will be further demonstrated by impedance measurements in the next section.

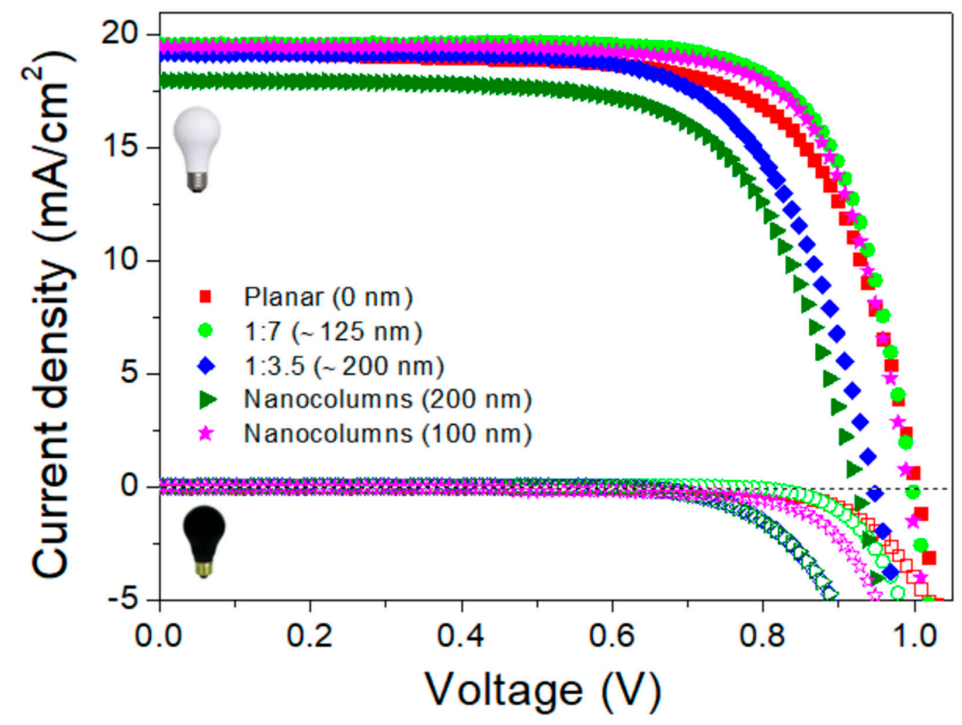

Figure 2. Current density-voltage $(J-V)$ characteristics of the best performing PSCs measured in dark and under illumination at AM 1.5G, $100 \mathrm{~mW} / \mathrm{cm}^{2}$ in reverse bias scans performed at $100 \mathrm{mV} \mathrm{s}^{-1}$, for different electron selecting layers. Hollow symbols indicate the dark current of the different ESL-based devices.

However, an ESL based on non-planar structure helps to minimize the hysteresis. As shown in Table S3, all non-planar devices show a hysteresis index (HI) of around $0.1-0.2$, whereas a value of 0.48 was found for planar devices.

$\mathrm{HI}$ values for the $\mathrm{MAPbI}_{3}$ based PSCs using different ESLs were calculated (Table S3) along with the $J-V$ parameters in forward and reverse directions for the best-performing device. Hysteresis 
behavior has been attributed to several causes, such as ionic migration, charge accumulation at selective contacts interfaces or distortion of the octahedral structure, or a combination of all of these factors. Recently, research direction has been focused on the slow processes occurring in the PSCs to study possible cause of hysteresis. The charge accumulation at the $\mathrm{TiO}_{2} /$ perovskite interface coupled with ionic migration may cause this phenomenon $[23,30,38]$.

Table 1. $J-V$ characteristics parameters of best-performing device based on $\mathrm{MAPbI}_{3}$ perovskite with different electron selecting layer. ${ }^{*}$ The value in parenthesis depicts the thickness used.

\begin{tabular}{|c|c|c|c|c|}
\hline Device Configuration * & $V_{o c}(\mathrm{mV})$ & $J_{\mathrm{sc}}\left(\mathrm{mA} / \mathrm{cm}^{2}\right)$ & Fill Factor (\%) & Efficiency (\%) \\
\hline Planar (0 nm) & 1000 & 19.28 & 69.04 & 13.45 \\
\hline $\mathrm{mp}-1: 3.5(\sim 200 \mathrm{~nm})$ & 940 & 19.15 & 68.60 & 12.42 \\
\hline mp-1:7 ( 125 nm) & 990 & 19.55 & 75.07 & 14.61 \\
\hline Nanocolumns (200 nm) & 920 & 17.94 & 68.07 & 11.26 \\
\hline Nanocolumns (100 nm) & 990 & 19.44 & 74.47 & 14.35 \\
\hline
\end{tabular}

In order to unravel the charge dynamics depending on the different ESLs, IS experiments were performed. This technique provides information about various internal processes occurring in working devices in different operation conditions and offers the possibility of analyzing interfacial and bulk processes separately. The resistive and capacitive processes occurring in the device are related to bulk and interfacial processes such as charge transport, accumulation, recombination and ion-mediated processes. Charge accumulation and ion migration can be probed by IS, and both processes are possibly interconnected and contribute to the hysteresis behavior. Charge imbalance also promotes an intrinsic instability, along with an irrational interface, both of which can accelerate the degradation of the fabricated devices. In our case, we have observed that devices with higher thickness (non-planar devices) of the ESL exhibited smaller values of HI than planar devices.

Figure 3 shows the apparent capacitance versus frequency plots, illustrating the different processes depending on the range of frequency. Low-frequency processes could be related to hysteresis behavior and thus we studied the variation of the low-frequency capacitance as a function of photo-voltage (Figure S3). The value of slope $\left(\mathrm{V}^{-1}\right)$ close to 22 indicates the existence of an accumulation regime. Our results suggest that planar configuration presents a higher slope than non-planar-based structure, suggesting a possible higher charge accumulation at the interface.

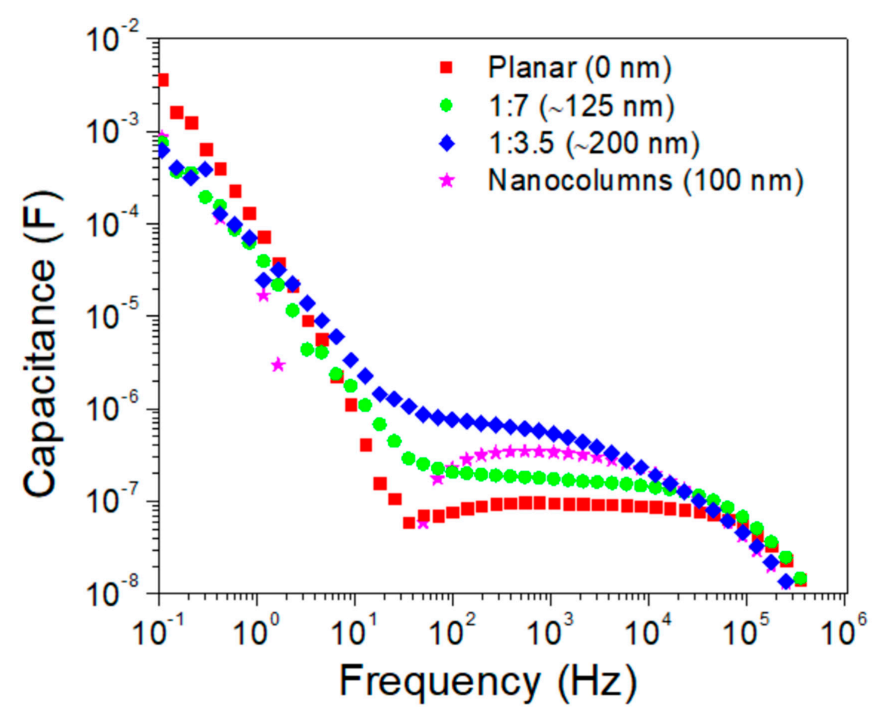

Figure 3. Frequency dependent apparent capacitance for PSCs using different electron selective layer at $0.9 \mathrm{~V}$. 
Furthermore, we undertook experiments to measure the charge dynamics that determine the functioning of PSCs. For this, we performed IS measurements with two different excitation wavelengths (blue and red) [37]. Based on the different penetration depths, which provoke a dissimilar charge generation profile with the use of two illumination wavelengths, the main purpose of this characterization was to detect in-homogeneities or the existence of a favored recombination region inside the solar device. By implementing this, we can study recombination processes occurring close to the electron (blue) and hole (red) in a more homogeneous way, as we will create different charge-generation profiles. As shown in Figure 4, two arcs with different characteristic frequencies can be distinguished for all the analyzed samples; one on the low frequency (LF) region (0.1-10 Hz), and one in the high-frequency $(\mathrm{HF})$ region $\left(10^{2}-10^{5} \mathrm{~Hz}\right)$. The semicircle at high frequencies can be directly linked to the recombination kinetics in the devices, while the semicircle at low frequencies, although also indirectly affected by recombination, is related to slow processes such as ionic migration or charge accumulation at the interfaces. We have found that IS measurements under red and blue light coincide with each other (Figure 4). By fitting the impedance response under blue and red illumination for $\mathrm{MAPbI}_{3} /$ Spiro devices to a simple $-\mathrm{R}_{\mathrm{S}}-\left(\mathrm{R}_{\mathrm{LF}},-\mathrm{CPE} \mathrm{C}_{1}\right)-\left(\mathrm{R}_{\mathrm{HF}},-\mathrm{CPE}_{2}\right)$-equivalent circuit, the $\mathrm{HF}$ (recombination) resistance can be extracted (Figure 5). In this analysis, a constant phase element (CPE) replaces an ideal capacitor in order to obtain a better fitting. The resulting $R_{H F}$ values under red and blue light excitation also coincide quite well, confirming that fresh samples do not possess any preferential recombination site. This fact points toward recombination processes occurring in the bulk of the perovskite layer, as previously reported [37].

Figure 6 shows the $\mathrm{R}_{\mathrm{HF}}$ values under red light excitation for all samples studied. Different slopes were identified depending on the ESL configuration. Previous studies reported the relationship between these slopes and the predominant recombination mechanism inside the solar device ( $\beta$ parameter in Figure 6) [37,39]. Our results (Table S4), suggest that the planar configuration presents a different or mixed recombination mechanism $(n=1 / \beta=1.41)$ with respect to the trap-limited recombination mechanism observed in the others studied configuration $(n=1 / \beta \sim 2)$. Considering the consistency between the recombination resistance data obtained with red and blue optical penetration profiles, which points toward bulk recombination, the different ideality factors obtained suggest that electrical features of perovskite depend on the nature of the ESL on which it is deposited. Even though the band gap of the perovskite remains unaltered, the crystallization process might be different, which will affect the transport and recombination features inside the active perovskite layer. It is well reported that the capacitance in the high-frequency range of the PSC is mostly governed by the geometrical component, which can be expressed as following; $C_{\mathrm{g}}=\varepsilon \cdot \varepsilon_{0} \cdot \mathrm{A} / \mathrm{d}$. Here $\varepsilon$ is the dielectric constant of the perovskite, $\varepsilon_{0}$ is the permittivity in vacuum, $A$ is the effective contact area and $d$ is the thickness of the absorber layer. The value of capacitance extracted from the high-frequency component (Figure S4) was constant on bias voltage; this is in accordance with its geometrical nature.

The role of ESL in devices' degradation was monitored, by recording $J-V$ measurements and incident photon-to-electron conversion efficiencies (IPCE) after 30 days (Figure S5a,b). We found that non-planar devices were more stable than planar ones. IPCE measurements of aged devices showed a systematic depletion of the photo generation in the full-wavelength range. Furthermore, following the methodology of previous works $[37,39]$, we also measured the open-circuit voltage $\left(V_{\text {oc }}\right)$ as a function of temperature ( $\mathrm{T}$ in $\mathrm{K}$ ) in order to extract the band gap of aged devices. Figure S6 represents the open-circuit voltage versus temperature curve of aged devices (stored under humid conditions for 30 days), and fits well into the straight line. The activation energy-which gives information about dominant recombination pathway-was estimated by extrapolation of the data to $\mathrm{T}=0 \mathrm{~K}$. It can be observed that the calculated band gaps show increment with respect to fresh devices ( $E_{\mathrm{g}}$ calculated by means of the absorbance measurements). These results are in accordance with the previous published results [37]. 

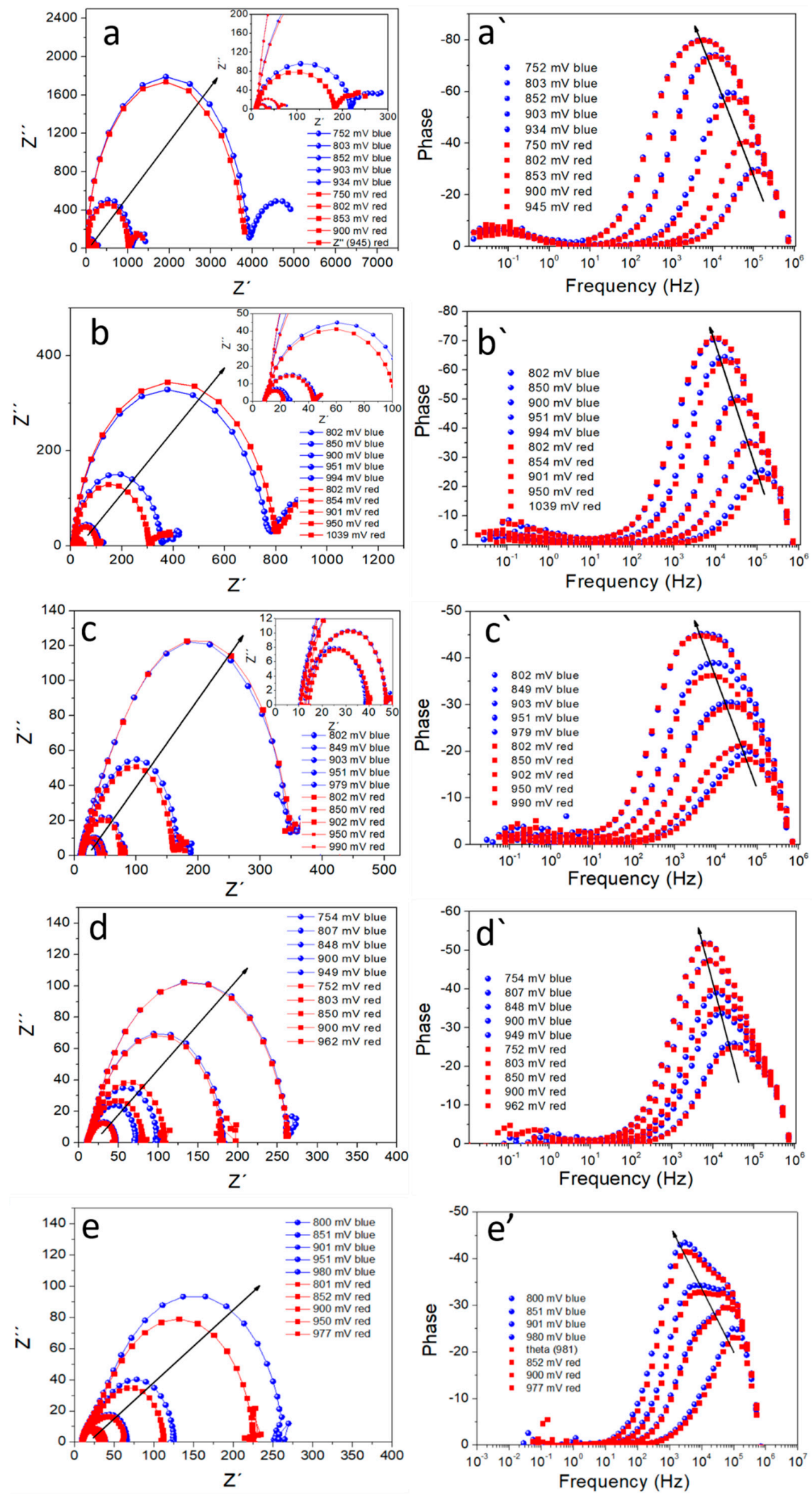

Figure 4. Nyquist (a-e) and Bode plots $\left(\mathbf{a}^{\prime}-\mathbf{e}^{\prime}\right)$ at different applied voltages for $\mathrm{CH}_{3} \mathrm{NH}_{3} \mathrm{PbI}_{3}$ perovskite solar cells using two excitation wavelengths, $\lambda_{\text {blue }}=465 \mathrm{~nm}$ and $\lambda_{\text {red }}=635 \mathrm{~nm}$. Different configurations are labeled as follows: $\left(\mathbf{a}, \mathbf{a}^{\prime}\right)$ planar, $\left(\mathbf{b}, \mathbf{b}^{\prime}\right)$ mesoporous 1:7, $\left(\mathbf{c}, \mathbf{c}^{\prime}\right)$ mesoporous 1:3.5, $\left(\mathbf{d}, \mathbf{d}^{\prime}\right)$ nanocolumns $100 \mathrm{~nm}$ and $\left(\mathbf{e}, \mathbf{e}^{\prime}\right)$ nanocolumns $200 \mathrm{~nm}$. Arrows indicate the evolution of the measurements when we measured from $V_{\mathrm{OC}}$ to lower values. 

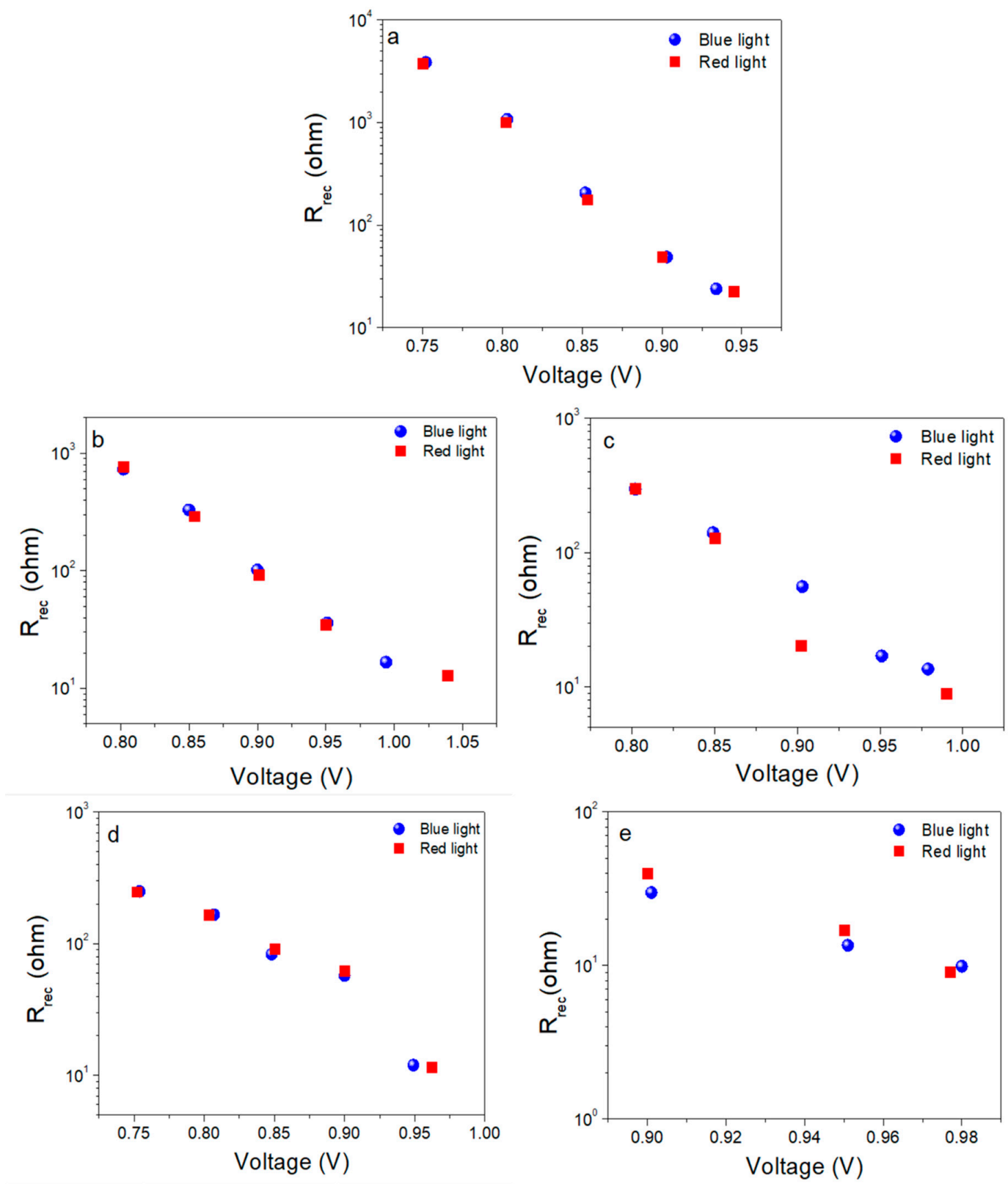

Figure 5. Recombination resistance plots (a-e) at different applied voltages for $\mathrm{CH}_{3} \mathrm{NH}_{3} \mathrm{PbI}_{3}$ perovskite using the two excitation wavelengths, $\lambda_{\text {blue }}=465 \mathrm{~nm}$ and $\lambda_{\text {red }}=635 \mathrm{~nm}$. Different configurations are labeled as follows: (a) planar, (b) mesoporous 1:7, (c) mesoporous 1:3.5, (d) nanocolumns $100 \mathrm{~nm}$ and (e) nanocolumns $200 \mathrm{~nm}$.

We propose that the increase in the band gap can be attributed to the emergence of lead iodide crystal due to a partial degradation of the perovskite material which can be located at the $\mathrm{TiO}_{2}$ /perovskite interface. It is worth noting that nanocolumns $(100 \mathrm{~nm})$ and mesoporous (1:7) present the lower deviation in $E_{\mathrm{g}}$ with respect to the initial values, indicating their better stability under aging. In the case of planar devices, a decrease in the band gap was noted. The decrease in $V_{\text {oc }}$, can be attributed to the formation of defect sites, which further induce new recombination sites. 


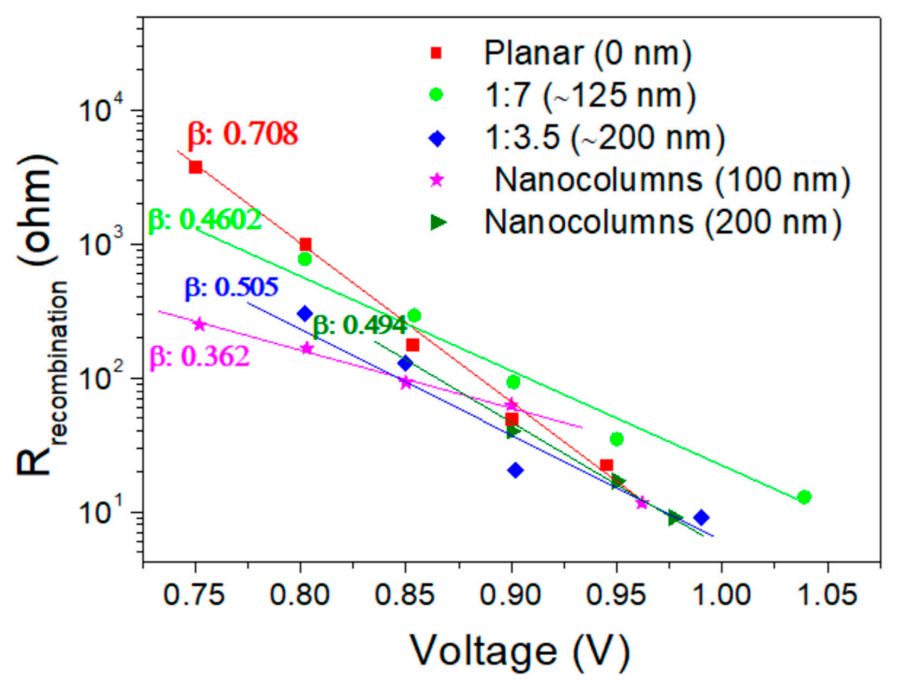

Figure 6. The representative recombination resistances $\left(\mathrm{R}_{\text {recombination }}\right)$ of the different $\mathrm{TiO}_{2}$ structures samples determined from IS under different applied bias voltages irradiated with red light.

\section{Conclusions}

Interfaces at the perovskite perform a crucial role in charge separation and transport for solar cells fabrication. Electron selective contacts, having different microstructure (3-dimensional and 1-dimensional) and thickness of porous $\mathrm{TiO}_{2}$ layer, were fabricated. The thickness and morphology of the electron selecting layer influenced the device performance and stability, possibly by affecting the perovskite crystallization process or the charge transfer at the interface. In the case of planar devices, a higher hysteresis index was observed, while both mesoporous (3D) and nanocolumns layer (1D) with $100 \mathrm{~nm}$ thickness gave good performance and stability.

By using impedance spectroscopy measurements, the samples were illuminated with different wavelengths (blue and red), and similar recombination resistance data were obtained irrespective of wavelength region, suggesting that the recombination process at open circuit occurs in the bulk of the perovskite layer. However, depending on the type of electron selective layer deposited, a different recombination path was observed as demonstrated by a different value of ideality factor, suggesting that electrical features of a perovskite layer depend on the nature of the ESL on which they are deposited. This work contributes to an understanding of the role of electron selective contact and its bearing on charge kinetics in perovskite solar cells.

Supplementary Materials: The following are available online at http:/ / www.mdpi.com/1996-1944/11/7/1073/ s1, Figure S1: Series resistance under 1 sun-illumination for different electron transport structures with reverse scans performed at $0.1 \mathrm{~V} \mathrm{~s}^{-1}$, Figure S2: (a) Absorption spectra of $\mathrm{CH}_{3} \mathrm{NH}_{3} \mathrm{PbI}_{3}$ perovskite infiltrated in different $\mathrm{TiO}_{2}$ structures. (b) Tauc plot to estimate optical band gap for perovskite films in the presence of $\mathrm{TiO}_{2}$ mesoporous or nanocolumnar structures having different thickness, Figure S3: Low frequency capacitance as a function of open circuit voltage of the PSCs using $\mathrm{TiO}_{2}$ electron transport layer, Figure S4: Geometric capacitance at different applied voltages for $\mathrm{CH}_{3} \mathrm{NH}_{3} \mathrm{PbI}_{3}$ perovskite using two excitation wavelengths $\lambda_{\text {blue }}=465 \mathrm{~nm}$ and $\lambda_{\text {red }}=635 \mathrm{~nm}$, Figure S5: J-V and IPCE measured after 30 days at humid conditions; (a) dark and under white light illumination, (b) IPCE and calculated integrated short circuit current, Figure S6: Open-circuit voltage as a function of temperature for PSCs with different $\mathrm{TiO}_{2}$ configurations under white light intensity of $14.15 \mathrm{~W} / \mathrm{m}^{2}, \mathrm{Table} \mathrm{S1}$ : Layer thicknesses extracted from SEM images of $\mathrm{MAPbI}_{3}$ perovskite solar cells using different thickness of $\mathrm{TiO}_{2}$ ESL, Table S2: Statistical data of photovoltaics parameters of $\mathrm{MAPbI}_{3}$-based PSCs, Table S3: J-V characteristic parameters values from the reverse and forward scan directions and calculated hysteresis index of the different ESL configurations, Table S4: Ideality factors of the perovskite solar cells acquired from impedance measurement using different electron transport configuration.

Author Contributions: M.S. planned the experiments and analyzed IS measurements and wrote the first draft of the paper. L.C. fabricated and characterized the devices. L.C.-B. performed one of the IS experiments, J.I. and J.A.A. provided guidance. S.K. coordinated and edited the draft for final document preparation, and S.A. directed and provide guidance to the research. All authors contributed to the completion of the final document. 
Funding: This work was supported by FP7-Marie curie international training network [Thinface-607232] and also partially supported by a European Research Council grant, [MOLEMAT-72760]. J.A.A., J.I. thanks Junta de Andalucía for financial support via grant FQM 1851 and FQM 2310, Ministerio de Economía y Competitividad of Spain under grants MAT2013-47192-C3-3-R and MAT2016-76892-C3-1-R and Red de Excelencia "Emerging Photovoltaic Technologies".

Acknowledgments: Authors thank Manuel Oliva and Agustin Rodríguez González-Elipe for nanocolumns preparation.

Conflicts of Interest: The authors declare no conflict of interest.

\section{References}

1. Tao, M. Inorganic Photovoltaic solar cells: Silicon and beyond. Electrochem. Soc. Interface 2008, 17, 30-35.

2. Green, M.A.; Ho-Baillie, A.; Snaith, H.J. The emergence of perovskite solar cells. Nat. Photonics 2014, 8, 506-514. [CrossRef]

3. Park, N.G. Perovskite solar cells: An emerging photovoltaic technology. Mater. Today 2015, 18, 65-72. [CrossRef]

4. Kim, H.S.; Im, S.H.; Park, N. Organolead halide perovskite: New horizons in solar cell research. J. Phys. Chem. C 2014, 118, 5615-5625. [CrossRef]

5. Jeon, N.J.; Noh, J.H.; Kim, Y.C.; Yang, W.S.; Ryu, S.; Seok, S.I. Solvent engineering for high-performance inorganic-organic hybrid perovskite solar cells. Nat. Mater. 2014, 13, 897-903. [CrossRef] [PubMed]

6. Jeon, N.J.; Noh, J.H.; Yang, W.S.; Kim, Y.C.; Ryu, S.; Seo, J.; Seok, S.I. Compositional engineering of perovskite materials for high-performance solar cells. Nature 2015, 517, 476-480. [CrossRef] [PubMed]

7. Kazim, S.; Nazeeruddin, M.K.; Grätzel, M.; Ahmad, S. Perovskite as light harvester: A game changer in photovoltaics. Angew. Chem. Int. Ed. 2014, 53, 2812-2824. [CrossRef] [PubMed]

8. NREL Efficiency Chart. Available online: http://www.nrel.gov/ncpv/images/efficiency_chart.jpg (accessed on 12 January 2018).

9. Burschka, J.; Pellet, N.; Moon, S.J.; Humphry-Baker, R.; Gao, P.; Nazeeruddin, M.K.; Grätzel, M. Sequential deposition as a route to high-performance perovskite-sensitized solar cells. Nature 2013, 499, 316-319. [CrossRef] [PubMed]

10. Liu, M.; Johnston, M.B.; Snaith, H.J. Efficient planar heterojunction perovskite solar cells by vapour deposition. Nature 2013, 501, 395-398. [CrossRef] [PubMed]

11. Sutherland, B.R.; Hoogland, S.; Adachi, M.M.; Kanjanaboos, P.; Wong, C.T.O.; McDowell, J.J.; Xu, J.; Voznyy, O.; Ning, Z.; Houtepen, A.J.; et al. Perovskite thin films via atomic layer deposition. Adv. Mater. 2015, 27, 53-58. [CrossRef] [PubMed]

12. Barrows, A.T.; Pearson, A.J.; Kwak, C.K.; Dunbar, A.D.F.; Buckley, A.R.; Lidzey, D.G. Efficient planar heterojunction mixed-halide perovskite solar cells deposited via spray-deposition. Energy Environ. Sci. 2014, 7, 2944-2950. [CrossRef]

13. Pellet, N.; Gao, P.; Gregori, G.; Yang, T.Y.; Nazeeruddin, M.K.; Maier, J.; Grätzel, M. Mixed-organic-cation perovskite photovoltaics for enhanced solar-light harvesting. Angew. Chem. Int. Ed. 2014, 53, 3151-3157. [CrossRef] [PubMed]

14. Cho, K.T.; Paek, S.; Grancini, G.; Carmona, C.R.; Gao, P.; Lee, Y.H.; Nazeeruddin, M.K. Highly efficient perovskite solar cells with a compositional engineered perovskite/hole transporting material interface. Energy Environ. Sci. 2017, 10, 621-627. [CrossRef]

15. Abate, A.; Saliba, M.; Hollman, D.J.; Stranks, S.D.; Avolio, R.; Petrozza, A.; Snaith, J. Supramolecular Halogen Bond Passivation of Organometal-Halide Perovskite Solar Cells. Nano Lett. 2014, 14, 3247-3254. [CrossRef] [PubMed]

16. Hwang, I.; Jeong, I.; Lee, J.; Ko, M.J.; Yong, K. Enhancing Stability of Perovskite Solar Cells to Moisture by the Facile Hydrophobic Passivation. ACS Appl. Mater. Interfaces 2015, 7, 17330-17336. [CrossRef] [PubMed]

17. Hao, F.; Stoumpos, C.C.; Liu, Z.; Chang, R.P.H.; Kanatzidis, M.G. Controllable perovskite crystallization at a gas-solid interface for hole conductor-free solar cells with steady power conversion efficiency over $10 \%$. J. Am. Chem. Soc. 2014, 136, 16411-16419. [CrossRef] [PubMed]

18. Bhachu, D.S.; Scanlon, D.O.; Saban, E.J.; Bronstein, H.; Parkin, I.P.; Carmalt, C.J.; Palgrave, R. Scalable Route to $\mathrm{CH}_{3} \mathrm{NH}_{3} \mathrm{PbI}_{3}$ Perovskite Thin Films by Aerosol Assisted Chemical Vapor Deposition. J. Mater. Chem. A 2015, 3, 9071-9073. [CrossRef] 
19. Yin, J.; Qu, H.; Cao, J.; Tai, H.; Li, J.; Zheng, N. Vapor-assisted crystallization control toward high performance perovskite photovoltaics with over 18\% efficiency in the ambient atmosphere. J. Mater. Chem. A 2016, 4, 13203-13210. [CrossRef]

20. Chen, Q.; Zhou, H.; Hong, Z.; Luo, S.; Duan, H.-S.; Wang, H.-H.; Liu, Y.; Li, G.; Yang, Y. Planar Heterojunction Perovskite Solar Cells via Vapor-Assisted Solution Process. J. Am. Chem. Soc. 2013, 136, 622-625. [CrossRef] [PubMed]

21. Kirchartz, T.; Staub, F.; Rau, U. Impact of Photon-Recycling on the Open-Circuit Voltage of Metal Halide Perovskite Solar Cells. ACS Energy Lett. 2016, 1, 731-739. [CrossRef]

22. Yan, W.; Li, Y.; Li, Y.; Ye, S.; Liu, Z.; Wang, S.; Bian, Z.; Huang, C. High-performance hybrid perovskite solar cells with open circuit voltage dependence on hole-transporting materials. Nano Energy 2015, 16, 428-437. [CrossRef]

23. Wang, Y.; Wang, H.Y.; Han, J.; Yu, M.; Hao, M.Y.; Qin, Y.; Fu, L.M.; Zhang, J.P.; Ai, X.C. The Influence of Structural Configuration on Charge Accumulation, Transport, Recombination, and Hysteresis in Perovskite Solar Cells. Energy Technol. 2017, 5, 442-451. [CrossRef]

24. Baena, J.P.C.; Steier, L.; Tress, W.; Saliba, M.; Neutzner, S.; Matsui, T.; Giordano, F.; Jacobsson, T.J.; Kandada, A.R.S.; Zakeeruddin, S.M.; et al. Highly efficient planar perovskite solar cells through band alignment engineering. Energy Environ. Sci. 2015, 8, 2928-2934. [CrossRef]

25. Choi, J.J.; Yang, X.; Norman, Z.M.; Billinge, S.J.L.; Owen, J.S. Structure of methylammonium lead iodide within mesoporous titanium dioxide: Active material in high-performance perovskite solar cells. Nano Lett. 2014, 14, 127-133. [CrossRef] [PubMed]

26. Meng, L.; You, J.; Guo, T.-F.; Yang, Y. Recent Advances in the Inverted Planar Structure of Perovskite Solar Cells. Acc. Chem. Res. 2016, 49, 155-165. [CrossRef] [PubMed]

27. Murugadoss, G.; Mizuta, G.; Tanaka, S.; Nishino, H.; Umeyama, T.; Imahori, H.; Ito, S. Double functions of porous $\mathrm{TiO}_{2}$ electrodes on $\mathrm{CH}_{3} \mathrm{NH}_{3} \mathrm{PbI}_{3}$ perovskite solar cells: Enhancement of perovskite crystal transformation and prohibition of short circuiting. APL Mater. 2014, 2, 081511. [CrossRef]

28. Li, M.-H.; Hsu, C.-W.; Shen, P.-S.; Cheng, H.-M.; Chi, Y.; Chen, P.; Guo, T.-F. Novel spiro-based hole transporting materials for efficient perovskite solar cells. Chem. Commun. 2015, 51, 15518-15521. [CrossRef] [PubMed]

29. Qin, P.; Domanski, A.L.; Chandiran, A.K.; Berger, R.; Butt, H.-J.; Dar, M.I.; Moehl, T.; Tetreault, N.; Gao, P.; Ahmad, S.; et al. Yttrium-substituted nanocrystalline $\mathrm{TiO}_{2}$ photoanodes for perovskite based heterojunction solar cells. Nanoscale 2014, 6, 1508-1514. [CrossRef] [PubMed]

30. Cojocaru, L.; Uchida, S.; Jayaweera, P.V.V.; Kaneko, S.; Wang, H.; Nakazaki, J.; Kubo, T.; Segawa, H. Effect of $\mathrm{TiO}_{2}$ Surface Treatment on the Current-Voltage Hysteresis of Planar-Structure Perovskite Solar Cells Prepared on Rough and Flat Fluorine-Doped Tin Oxide Substrates. Energy Technol. 2017, 5, 1762-1766. [CrossRef]

31. Giordano, F.; Abate, A.; Baena, J.P.C.; Saliba, M.; Matsui, T.; Im, S.H.; Zakeeruddin, S.M.; Nazeeruddin, M.K.; Hagfeldt, A.; Graetzel, M. Enhanced electronic properties in mesoporous $\mathrm{TiO}_{2}$ via lithium doping for high-efficiency perovskite solar cells. Nat. Commun. 2016, 7, 10379. [CrossRef] [PubMed]

32. Abdi-Jalebi, M.; Dar, M.I.; Sadhanala, A.; Senanayak, S.P.; Giordano, F.; Zakeeruddin, S.M.; Grätzel, M.; Friend, R.H. Impact of a Mesoporous Titania-Perovskite Interface on the Performance of Hybrid Organic-Inorganic Perovskite Solar Cells. J. Phys. Chem. Lett. 2016, 7, 3264-3269. [CrossRef] [PubMed]

33. Kaake, L.G.; Barbara, P.F.; Zhu, X.Y. Intrinsic charge trapping in organic and polymeric semiconductors: A physical chemistry perspective. J. Phys. Chem. Lett. 2010, 1, 628-635. [CrossRef]

34. Guillén, E.; Ramos, F.J.; Anta, J.A.; Ahmad, S. Elucidating transport-recombination mechanisms in perovskite solar cells by small-perturbation techniques. J. Phys. Chem. C 2014, 118, 22913-22922. [CrossRef]

35. Salado, M.; Oliva-Ramirez, M.; Kazim, S.; González-Elipe, A.R.; Ahmad, S. 1-dimensional $\mathrm{TiO}_{2}$ nano-forests as photoanodes for efficient and stable perovskite solar cells fabrication. Nano Energy 2017, 35, 215-222. [CrossRef]

36. Lopez-Santos, C.; Alvarez, R.; Garcia-Valenzuela, A.; Rico, V.; Loeffler, M.; Gonzalez-Elipe, A.R.; Palmero, A. Nanocolumnar association and domain formation in porous thin films grown by evaporation at oblique angles. Nanotechnology 2016, 27, 395702. [CrossRef] [PubMed]

37. Contreras-Bernal, L.; Salado, M.; Todinova, A.; Calio, L.; Ahmad, S.; Idígoras, J.; Anta, J.A. Origin and Whereabouts of Recombination in Perovskite Solar Cells. J. Phys. Chem. C 2017, 121, 9705-9713. [CrossRef] 
38. Contreras, L.; Idígoras, J.; Todinova, A.; Salado, M.; Kazim, S.; Ahmad, S.; Anta, J.A. Specific cation interactions as the cause of slow dynamics and hysteresis in dye and perovskite solar cells: A small-perturbation study. Phys. Chem. Chem. Phys. 2016, 18, 31033-31042. [CrossRef] [PubMed]

39. Leong, W.L.; Ooi, Z.-E.; Sabba, D.; Yi, C.; Zakeeruddin, S.M.; Graetzel, M.; Gordon, J.M.; Katz, E.A.; Mathews, N. Identifying Fundamental Limitations in Halide Perovskite Solar Cells. Adv. Mater. 2016, 28, 2439-2445. [CrossRef] [PubMed]

2018 by the authors. Licensee MDPI, Basel, Switzerland. This article is an open access article distributed under the terms and conditions of the Creative Commons Attribution (CC BY) license (http://creativecommons.org/licenses/by/4.0/). 